\title{
Three year follow up of patients with gastrooesophageal reflux disease
}

\author{
N E Schindlbeck, A G Klauser, G Berghammer, W Londong, S A Müller-Lissner
}

\begin{abstract}
Data on the natural course of gastrooesophageal reflux disease are sparse. One hundred and sixty six patients with typical reflux symptoms (heartburn and/or acid regurgitation) and pathologic pH monitoring (reflux time $>\mathbf{8} \cdot 2 \%$ upright and/or $>\mathbf{3 . 0} \%$ supine) were studied. The patients were followed up by questionnaire and interview for a mean of 41 (seven to 86) months after diagnosis of reflux disease. Ten patients had died of diseases not reflux related. In $117(75 \%)$ of the remaining 156 patients data on the course of gastrooesophageal reflux disease could be obtained. In 12 patients anti reflux surgery had been performed. Forty one (39\%) of the remaining 105 patients have stopped taking medical therapy, in 13 of these patients symptoms had completely disappeared. Sixty four patients continued on medication (40 on demand, 24 regularly). When asked how their symptoms would be if they completely stopped medication, 71 patients considered their symptoms to be equal or worse and 21 patients to be improved as compared with the initial investigation. Patients with persisting symptoms at follow up had significantly more supine reflux $(\mathbf{p}<\mathbf{0 . 0 5})$ at the initial $\mathbf{p H}$ monitoring as compared with patients with improved symptoms. The presence and grade of oesophageal erosions at initial endoscopy, duration of symptoms, age, sex, and smoking habits had no influence on the course of gastrooesophageal reflux disease. In conclusion, reflux symptoms disappear only in a minority of patients with proven gastrooesophageal reflux disease. More than half of all patients continue medication, either on demand or regularly. Severe supine reflux is an unfavourable prognostic factor.
\end{abstract}

(Gut 1992; 33: 1016-1019)

Occasional mild heartburn is one of the most common symptoms reported by otherwise 'healthy' subjects.' The prevalence of heartburn has been estimated between $7 \%$ on a daily basis and $36 \%$ at least once a month. ${ }^{2}$ Until $\mathrm{H}_{2}$ blockers were generally available the medical treatment of chronic reflux symptoms was inferior to surgical management. ${ }^{3}$ Introduction of $\mathrm{H}_{2}$ blockers has substantially improved success of medical therapy. There are numerous studies which have shown that short term treatment with $\mathrm{H}_{2}$ blockers and omeprazole can effectively heal severe reflux oesophagitis and improve reflux symptoms. ${ }^{+6}$ Relapse of oesophagitis and symptoms, however, is frequently observed. ${ }^{+6}$ Thus, gastrooesophageal reflux disease obviously cannot be healed with short term treatment.
Data on longterm outcome of gastrooesophageal reflux are sparse. Available studies either were based on small samples ${ }^{7}$ or did not meet modern inclusion criteria of patients. ${ }^{89}$ The aim of the present study, therefore, is (i) to follow up a large and well defined patient sample with proven gastrooesophageal reflux disease and (ii) to identify prognostic parameters which can predict the course of reflux disease.

\section{Methods}

\section{PATIENTS}

Between 1983 and 1990, 708 patients were investigated for gastrooesophageal reflux disease in our laboratory. From these, all patients with typical symptoms of gastrooesophageal reflux disease (heartburn and/or acid regurgitation) for at least one month before the study and a pathologic 24 hour $\mathrm{pH}$ monitoring (see below) were selected. Patients with previous upper gastrointestinal surgery such as cholecystectomy, gastric resection, or selective proximal vagotomy were excluded. One hundred and sixty six consecutive patients remained with proven gastrooesophageal reflux disease were included in the study.

\section{INDEX ASSESSMENT}

A standardised questionnaire was completed for each patient during a personal interview with an experienced gastroenterologist who asked about age, smoking habits, and type, frequency and duration of symptoms.

\section{TWENTY FOUR HOUR PH MONITORING}

Ambulatory 24 hour pH monitoring was performed as previously described. ${ }^{10}$ Briefly, a combined glass electrode (440 M4, Ingold, Urdorf Switzerland, external diameter at the tip $4 \mathrm{~mm}$ ) was connected to a $\mathrm{pH}$ meter and initially positioned in the stomach of the supine patient. It was then slowly withdrawn until a sudden rise of $\mathrm{pH}$ from acid $(\mathrm{pH}<4)$ to neutral $(\mathrm{pH}>6)$ was recorded on the $\mathrm{pH}$ meter. The $\mathrm{pH}$ rise could be identified in each case. The electrode was placed $5 \mathrm{~cm}$ above the sudden $\mathrm{pH}$ rise by anchoring the cable to the patients nose with adhesive tape. It is controversial whether the electrode in $\mathrm{pH}$ monitoring can be placed without prior manometry. ${ }^{11-1+}$ In the present study, manometry has been replaced by the identification of the sudden $\mathrm{pH}$ rise at the oesophagogastric junction, as the accuracy of this simple method to position the electrode has been validated compared with manometric, endoscopic, and radiologic methods."12 Finally, the electrode was con- 
TABLE I Type and outcome of anti reflux surgery

\begin{tabular}{|c|c|c|c|c|}
\hline \multirow[b]{2}{*}{ Type of surgery } & \multicolumn{3}{|c|}{ Reflux symptoms } & \multirow{2}{*}{$\begin{array}{l}\text { Postoperative } \\
\text { dysphagia }\end{array}$} \\
\hline & None & Improved & Unchanged & \\
\hline Fundoplication & 2 & - & - & 1 \\
\hline Gastropexy & - & 2 & 1 & - \\
\hline Vagotomy & 1 & - & - & - \\
\hline Fundoplication + vagotomy & - & 1 & $\dot{-}$ & - \\
\hline Gastropexy+ vagotomy & 2 & 1 & 1 & - \\
\hline Billroth II resection & $\overline{1}$ & - & - & - \\
\hline $\mathrm{n}=12,8$ men, 4 women & 6 & 4 & 2 & 1 \\
\hline
\end{tabular}

TABLE II Symptomatic success of medical treatment as assessed by the patient

\begin{tabular}{|c|c|c|c|c|c|c|}
\hline \multirow{2}{*}{$\begin{array}{l}\text { Type of } \\
\text { medication }\end{array}$} & \multicolumn{5}{|c|}{ Success } & \multirow[b]{2}{*}{$\Sigma$} \\
\hline & $?$ & None & Moderate & Good & Excellent & \\
\hline Antacids & 2 & 1 & 10 & 15 & 3 & 31 \\
\hline $\mathrm{H}_{2}$ blocker & 1 & 0 & 4 & 13 & 2 & 20 \\
\hline Omeprazole & 0 & 0 & i & 1 & 1 & 3 \\
\hline Pirenzepine & 0 & 0 & 1 & 0 & 3 & 4 \\
\hline Prokinetics & 0 & 0 & 0 & 3 & 0 & 3 \\
\hline \multirow{2}{*}{ Other drugs } & 0 & 0 & 1 & 1 & 1 & 3 \\
\hline & 3 & 1 & 17 & 33 & 10 & 64 \\
\hline
\end{tabular}

?=unknown/unclear.
In addition, data on actual symptoms as compared with index investigation, medication (type, duration, success), endoscopy, and eventual anti reflux surgery were obtained. If endoscopy or anti reflux surgery had been performed, the medical records were obtained.

\section{STATISTICAL ANALYSIS}

Data are given as means (SD) and, if appropriate, as medians and ranges. The Wilcoxon's rank-sum test for unpaired data and the $\chi^{2}$ test were used to test for statistically significant differences.

\section{Results}

Ten patients had died unrelated to reflux disease. In 117 (75\%, 85 men, 32 women) of the remaining 156 patients data on the course of gastrooesophageal reflux disease could be obtained. They were followed up for a mean of $41(7-86)$ months. The mean age ranged from 19 to 80 years with a median of 52 years. In 12 patients anti reflux surgery had been performed. The type and outcome of surgery is summarised in Table I.

In the remaining 105 patients $(77$ men, 28 women) the median overall duration of symptomatic reflux disease was 10 (one to 50) years at follow up. Thirty nine per cent of the patients had stopped medication, and in only less than one third of these patients symptoms had completely disappeared. Sixty one per cent of the patients continued to take medication, either on demand or regularly (Fig 1). The success of the different types of medication is summarised in Table II. Antacids were significantly more often taken on demand, not regularly, than $\mathrm{H}_{2}$ blockers $(83 \%$ v 36\%, $\mathrm{p}<0.002)$.

Patients on medication (regular or on demand) were asked how their symptoms would be if they stopped all medication. Seventy one considered their symptoms to be equal or worse and 21 patients to be improved as compared with the index investigation (Fig 2).

Twenty four patients had an endoscopy both at the index assessment and at follow up. New appearance of erosions occurred as often as disappearance of erosions (Fig 3). were found in $11 \%$, linear confluent erosions (grade II) in 9\%, circumferential erosions (grade III) in $7 \%$, and an endobrachyoesophagus (grade IV) in $5 \%$ of the patients, respectively. Thus, in a total of $32 \%$ of the patients erosive oesophagitis was present. Patients with oesophageal erosions had significantly $(\mathrm{p}<0.05)$ more reflux (upright $18 \cdot 2 \%(2 \cdot 7 \%-59 \cdot 6 \%)$, supine $10 \cdot 1 \%(0 \cdot 0 \%-$ $98 \cdot 6 \%)$ ) as compared with patients without erosions (upright $12 \cdot 4 \%(0 \cdot 4 \%-69 \cdot 4 \%)$, supine $4 \cdot 2 \%(0 \cdot 0 \%-80 \cdot 7 \%))$.

\section{FOLLOW UP}

Follow up interviews were carried out between February and December 1990. The patients were invited to the reassessment by letter and if necessary by phone. The interview of the index assessment was repeated either by telephone or by personal interview at our laboratory. The questions of the index interview were repeated. treatment and how are the symptoms as compared with index investigation?

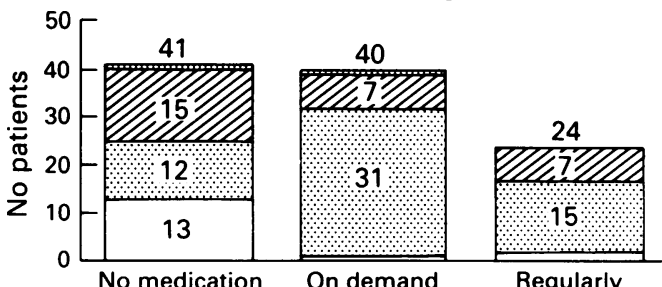

Schedule of medication

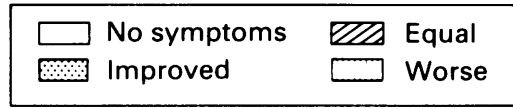

Symptoms at follow up

Figure 1: Numbers of patients on different treatment schedules and symptomatic success of treatment.
Do you continue medical antireflux 


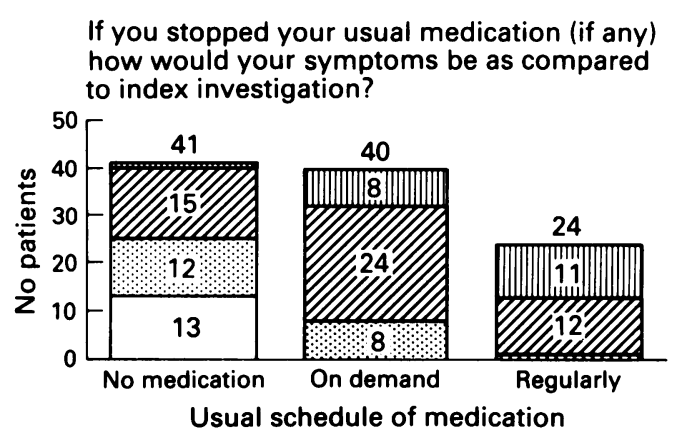

$\begin{array}{|ll|}\square \text { No symptoms } & \text { Eam Equal } \\ \text { Improved } & \text { ․m. Worse }\end{array}$

Symptoms at follow up

Figure 2: Development of symptoms without medication as estimated by the patients. The figures of the group with no medication are necessarily the same as in Figure 1.

PROGNOSTIC FACTORS

Patients with persisting symptoms at follow up had significantly more supine reflux $(\mathrm{p}<0.05)$ at the initial $\mathrm{pH}$ monitoring as compared with patients with improved symptoms (Table III). The presence and grade of oesophageal erosions at the initial assessment, duration of symptoms, age, sex, and smoking habits had no influence on the course of gastrooesophageal reflux disease.

\section{Discussion}

Anti reflux surgery was the most efficacious therapy for gastrooesophageal reflux disease until the advent of $\mathrm{H}_{2}$ receptor blockers. ${ }^{3}$ While studies on the success of short treatment treatment with various drugs are numerous ${ }^{5}$ information on what happens after stopping scheduled treatment are sparse. ${ }^{46}$ In these few studies, erosive oesophagitis recurred in a large proportion of patients within six months. Therefore, we wondered how the symptoms and the need for treatment developed after the initial diagnosis irrespective of the presence or absence of oesophageal erosions.

Some earlier treatment studies before modern medical treatment with $\mathrm{H}_{2}$ blockers, omeprazole, or prokinetics, may give some information

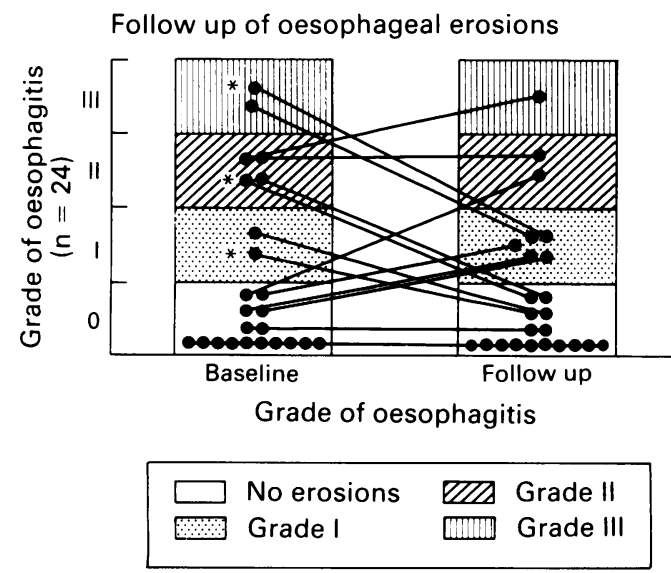

Figure 3: Correlation between endoscopic findings at the start of follow-up and in the course in 24 patients. An endobrachyoesophagus $\left({ }^{\star}\right)$ was present in three patients.
TABLE III Correlation between reflux at index assessment and symptoms in the course

\begin{tabular}{lll}
\hline & \multicolumn{3}{l}{ Symptoms in the course } \\
\cline { 2 - 3 }$\%$ Reflux time & None or improved $(n=34)$ & Equal or worse $(n=71)$ \\
\hline Upright & $12 \cdot 4(1 \cdot 4-69 \cdot 4)$ & $12 \cdot 3(0 \cdot 4-58 \cdot 2)$ \\
Supine & $2 \cdot 3(0 \cdot 0-32 \cdot 7)$ & $5 \cdot 0(0 \cdot 0-96 \cdot 6)^{\star}$ \\
\hline
\end{tabular}

Medians (range); ${ }^{\star}=\mathrm{p}<0.05 v$ group with symptoms improved.

on the 'natural course' of reflux disease. A study of $\operatorname{Rex}^{8}$ published in 1961 provided a 10 year follow up of patients with hiatal hernia (diagnosed by radiography) treated conservatively. During the 10 year follow up approximately $60 \%$ patients improved or became asymptomatic. Patients with minimal symptoms (dyspepsia, vague distress) showed improvement in $82 \%$ compared with only $39 \%$ of patients with 'oesophagitis' and symptoms such as dysphagia and regurgitation. Another study ${ }^{9}$ reported a disappearance of reflux disease in $35 \%$ of the patients. The major limitation of all these investigations was that the inclusion criteria have been based on radiographic findings of an hiatal hernia or on unspecific symptoms. Thus, one may argue that the patients with vague symptoms did in fact not have gastrooesophageal reflux disease at all and that the symptoms of true gastrooesophageal reflux disease persisted in the majority of cases. This view is corroborated by other studies which based the diagnosis gastrooesophageal reflux disease on reliable diagnostic standards - for example, endoscopy and/or oesophageal pH-metry. A randomised prospective study compared surgical therapy with a conservative management of patients with gastrooesophageal reflux disease over a period of 36 months. ${ }^{3}$ Excellent or good results were obtained in $73 \%$ of the surgically treated patients as compared with $19 \%$ of those treated conservatively. A study of Lieberman ${ }^{7}$ analysed the course of 20 medically treated patients with proven reflux disease during a 26 month follow up. After an initial intensive therapy with cimetidine and metoclopramide, 12 patients experienced a relapse of symptoms (nine patients when drug dosage were tapered or discontinued, three patients after a remission of longer than two years). Seven of the remaining eight patients were maintained 'asymptomatic' with occasional antacids (five patients) or cimetidine, $300 \mathrm{mg}$ at bedtime (two patients). In this study, therefore, only one patient really remained asymptomatic without any medication. Another study analysed a six months maintenance treatment with cimetidine or placebo in 24 patients. ${ }^{17}$ Sustained symptomatic relief was similar in both groups when only patients were considered who completed the observation period. Because four of 10 patients in the placebo group dropped out because of worsening symptoms, their data are therefore in accordance with our results. As a result of our inclusion criteria, namely pathologic $\mathrm{pH}$ monitoring and the specific symptoms heartburn and acid regurgitation, our patient sample consists of proven cases with reflux disease. About one third had erosive oesophagitis initially. Hence, our sample seems to be representative for patients with gastrooesopha- 
geal reflux disease. ${ }^{1}$ In one third of the patients with repeat endoscopy this gave discrepant results. Hence, erosions disappear and develop with similar frequency: they wax and wane. This explains the placebo healing rates in controlled drug studies in oesophagitis, which can be estimated at about $20 \%,{ }^{+5}$ and that healing of oesophagitis is not equivalent to healing of reflux disease. Less than one fourth of the patients treated conservatively had improved at follow up. About two thirds of our patients continued drug treatment during the observation period, either continuously or on demand. Similar results were obtained in a much smaller sample of reflux patients. ${ }^{7}$ About half of our patients used antacids (Table II). The reason may be that German practitioners are reluctant to prescribe $\mathrm{H}_{2}$ blockers and omeprazole because of their high cost. In addition, omeprazole is not approved for longterm treatment. Finally, the mode of administration and action of antacids seems more logical for occasional reflux symptoms than treatment with a drug with systemic action.

Our patients with anti reflux surgery in the follow up had severe symptoms, which did not sufficiently improve on medical therapy. Thus, if the operated patients are considered with the entire sample, spontaneous improvement of gastrooesophageal reflux disease is even more rare.

De Caestecker ${ }^{18}$ found that daytime gastrooesophageal reflux is an important factor for the development of erosive oesophagitis. We could confirm these results. In addition, we found that the severity of reflux is correlated with erosive oesophagitis, irrespective of the body position and the intake of meals. For the longterm outcome, however, only high supine reflux proved to be an unfavourable prognostic factor in reflux disease. We were unable to define other prognostic factors - for example, the duration of symptomatic reflux disease and the grade of oesophageal erosions did not correlate with the course of symptoms. This confirms previous findings that neither the duration of symptoms before diagnosis ${ }^{8}$ nor the endoscopic findings had an influence on the course of reflux disease.

In conclusion, reflux symptoms disappear only in a minority of patients with proven gastrooesophageal reflux disease over the years. More than half of all patients continue medication, either on demand or regularly. High supine reflux is an unfavourable prognostic factor in gastrooesophageal reflux disease.

Supported by W Sanderstiftung 88.033.1.

1 Heading RC. Epidemiology of oesophageal reflux disease. Scand F Gastroenterol 1989; 24 (suppl 168): 33-7.

2 Nebel OT, Fornes MF, Castell DO. Symptomatic gastroesophageal reflux: incidence and precipitating factors. Dig Dis Sci 1976; 21: 953-6.

3 Behar J, Sheahan DG, Biancani P, Spiro HM, Storer EH. Medical and surgical management of reflux esophagitis. NEngl F Med 1975; 293: 263-8.

4 Koelz HR, Birchler R, Bretholz A, Bron B, Capitaine Y, Delmore $\mathrm{G}$, et al. Healing and relapse of reflux esophagitis during treatment with ranitidine. Gastroenterology 1986; 91 : during trea
$1198-205$.

5 Koelz HR. Treatment of reflux esophagitis with H2-blockers, antacids and prokinetic drugs. An analysis of randomized clinical trials. Scand f Gastroenterol 1989; 24 (suppl 156) 25-36

6 Hetzel DJ, Dent J, Reed WD, Narielvala FM, Mackinnon M, McCarthy $\mathrm{JH}$, et al. Healing and relapse of severe peptic esophagitis after treatment with omeprazole. Gastroenterology 1988; 95: 903-12.

7 Lieberman DA. Medical therapy for chronic reflux esophagitis. Arch Intern Med 1987; 147: 1717-20.

8 Rex JC, Andersen HA, Bartholomew LG, Cain JC. Esophageal hiatal hernia - A 10-Year Study of medically treated cases. FAMA 1961; 178: 271-4.

9 Palmer ED. The hiatus hernia-esophagitis-esophageal Palmer ED. The hiatus hernia-esophagitis-esophageal
stricture complex: twenty-year prospective study. Am $\mathcal{f}$ Med stricture complex:

10 Schindlbeck NE, Heinrich $\mathrm{Ch}$, König A, Dendorfer A, Pace F, Müller-Lissner SA. Optimal thresholds, sensitivity and specificity of long-term $\mathrm{pH}$-metry for the detection of gastroesophageal reflux disease. Gastroenterology 1987; 93 $85-90$

11 Rokkas TH, Anggiansah A, Dorrington L, Owen WJ, Sladen $\mathrm{GE}$. Accurate positioning of the $\mathrm{pH}$-probe in the oesophagus without manometry. Ital f Gastroenterol 1987; 19: 176-8.

12 Klauser AG, Schindlbeck NE, Müller-Lissner SA. Esophageal 24-h pH monitoring: Is prior manometry necessary for correct positioning of the electrode? Am f Gastroenterol 1990; 85: 1463-7.

13 DeMeester TR, Wang C-I, Wernly JA, Pellegrini CA, Little AG, Klementschitsch $\mathrm{P}$, et al. Technique, indications, and clinical use of 24 hour esophageal pH
Cardiovasc Surg 1980; 79: 656-70.

14 Marples MI, Mughal M, Bancewicz J. Can an esophageal pH electrode be accurately positioned without manometry? In Siewert JR, Hölscher AH, eds. Diseases of the esophagus. Berlin: Springer, 1987: 789-91.

15 Schindlbeck NE, Ippisch H, Klauser AG, Müller-Lissner SA Which pH-threshold is best in esophageal pH-monitoring. Am f Gastroenterol 1991; 86: 1138-41.

16 Savery M, Miller G. The Oesophagus. Solothurn: Gassmann, 1977.

17 Kaul B, Petersen H, Erichsen H, Myrvold HE, Grette K, Halvorsen T, Fiøsne U. Gastroesophageal reflux disease. Acute and maintenance treatments with cimetidine. Scand $\mathcal{F}$ Acute and maintenance treatment

18 De Caestecker JS, Blackwell JN, Pryde A, Heading RC Daytime gastro-oesophageal reflux is important in oesophagitis. Gut 1987; 28: 519-26. 